\section{The Influence of Gardening Activities on Self-reported Health Problems, Allergies, and Body Mass Index}

\author{
Coleman L. Etheredge ${ }^{1,4}$, Tina M. Waliczek ${ }^{2}$, and Jayne M. Zajicek
}

ADDITIONAL INDEX wORDs. BMI, chronic illness, human issues in horticulture, biophilia, obesity, overweight

SUMMARY. In the last quarter century, the epidemic of overweight and obese Americans has increased strikingly. This, in turn, has caused a substantial rise in the risk of cardiovascular diseases, cholesterol, hypertension, osteoarthritis, stroke, type II diabetes, specific forms of cancer, and other diseases. The main purpose of this research was to investigate the influence of gardening activities on activity levels, body mass index (BMI), allergies, and reported overall health of gardeners and nongardeners. The sample population was drawn from two sources: an online survey and an identical paper-pencil formatted survey, which was distributed to church, garden, and community service groups within Texas and parts of the midwestern United States. A total of 1015 people participated in the study. Results from this study indicated nongardeners were less physically active when compared with gardeners. However, frequency of gardening did not have a statistically significant impact on gardeners' BMI. There was also no difference in BMI between gardeners and nongardeners. Gardeners indicated having more frequently reoccurring symptoms for "ear infection/ear ache," "high cholesterol," "kidney stone," "gallstones," and "arthritis," indicating gardening may be being used as a distraction therapy, helping gardeners to cope with pain and remain active when other forms of exercise may not be an option. There was no statistically significant difference in incidence of allergies between gardeners and nongardeners.

I $\mathrm{n}$ the last quarter century, the epidemic of overweight and obese Americans has increased strikingly. According to the Centers for Disease Control and Prevention (CDC), $\approx 34.9 \%$ of adults in the United States are obese (CDC, 2014). The President's Council on Physical Fitness and Sports estimates nearly three of five American adults carry unhealthy or excess weight [U.S. Department of Health and Human Services (HHS), 2008 ]. In addition, roughly $7.8 \%$ of people 18 years old and over in the United States have hay fever AAAAI (2015). Studies have found that people with allergy symptoms rate their quality of life lower, have more missed work days and less productivity at work and school (Bielory et al., 2014).

Obesity is far more perilous than most people think because it disables and kills by substantially raising the

\footnotetext{
${ }^{1}$ Assistant Professor, Department of Plant and Soil Sciences, Mississippi State University, Starkville, MS 39759

${ }^{2}$ Professor, Department of Agriculture, Texas State University, San Marcos, TX 78666

${ }^{3}$ Professor, Department of Horticultural Sciences, Texas A\&M University, College Station, TX 77845

${ }^{4}$ Corresponding author. E-mail: cle248@msstate.edu. doi: 10.21273/HORTTECH03546-16
}

risk of cardiovascular disease, cholesterol, hypertension, osteoarthritis, stroke, type II diabetes, specific forms of cancer, and other diseases (CDC, 2007; Weisberg, 2002). In addition, obesity is associated with increases in all causes of mortality (HHS, 2001; Ogden et al., 2006; Weisberg, 2002).

The economic consequences of obesity affect both the individual and the nation. In 2008, medical expenses for treating obesity were nearly $\$ 147$ billion; the medical cost for those people who were obese was \$1429 higher annually when compared with It has been determined that a multitude of factors likely contribute to obesity, one of which is prevalence of physical inactivity (Kopelman, 2000).

Therefore, agreement has been reached that weight management through regular physical activity is one method that can help reduce this epidemic. To promote and maintain health and reduce the incidence of overweight and obese people in society, recommendations have been made suggesting adults engage in physical activity (of low-moderate intensity) for a minimum of 30-45 min, 3-5 d per week (Haskell et al., 2007; HHS, those of normal weight (CDC, 2014).
2001; Nelson et al., 2007; Pate et al., 1995).

People all over the world suffer with allergy symptoms on a daily basis. According to AAAAI (2015), worldwide, allergies affect between $10 \%$ and $30 \%$ of the population. Allergy symptoms, such as stuffy, itchy, or runny nose and watery, itchy eyes, are common in the United States (Singh et al., 2010). A report conducted in 2012 found 17.6 million, $(7.6 \%)$ adults and 6.6 million, $(9.0 \%)$ children, were diagnosed with hay fever in the past 12 months (AAAAI, 2015).

Asthma is a chronic health problem closely associated with allergies, which can cause mental and social problems in addition to physical symptoms (Coban and Aydemir, 2014). About 25 million or $8 \%$ of the U.S. population suffered from asthma in 2009. This was an increase from 20 million or $7 \%$ in 2001. Overall, an estimated 300 million people worldwide suffer from asthma (AAAAI, 2015). In 2010, asthma was linked to 3404 deaths in the United States. About 250,000 people die prematurely each year from asthma (AAAAI, 2015).

Research comparing gardeners to nongardeners (Waliczek et al., 2005) determined gardening influences perceptions of life satisfaction in terms of overall health and zest for life. Research has shown gardening reduces the stress of a fatigued mind (Kaplan and Kaplan, 1982). In addition, gardening has physical benefits and has been classified as a moderate physical activity (Nykamp, 1999; Taylor, 1990). Most gardening tasks, which include digging, raking, weeding, mulching, hoeing, sowing seed, harvesting, watering, mixing growing medium, and planting transplants are moderate to high-intensity physical activities (Park et al., 2014). In addition, gardening is an activity influencing whole body bone mineral density since it incorporates weight-bearing motions involving all muscle groups (Turner et al., 2002).

It is generally accepted that community gardening and growing food for personal use may increase physical activity and benefit individual diets (Burges-Watson and Moore, 2011; Lake and Townshend, 2006). A meta-analysis investigating gardening and vegetable consumption in children found overall knowledge of nutrition increases when children are 
exposed to a nutrition education program. Furthermore, when children were exposed to gardening programs, their vegetable and fruit consumption increased (Langellotto and Gupta, 2012). Another study on community gardeners found that families who gardened increased their consumption of vegetables and fruits, with adults increasing their consumption 4-fold and children increasing their vegetable and fruit consumption 3-fold (Carney et al., 2011). Sommerfeld et al. (2010) found evidence suggesting that gardening intervention programs later in an individual's life would be an effective method of increasing fruit and vegetable consumption in older adults.

The purpose of this research was to investigate the influence of gardening activities on activity levels, BMI, allergies, and reported overall health in gardeners and nongardeners.

\section{Materials and methods}

SAmple Population. The sample population used in this study was a random selection of gardeners and nongardeners 18 years of age and older. Participants were drawn from two sources. An online survey was created using Survey Monkey (Palo Alto, CA) and posted for 4 months on social media websites and spread through word of mouth. An identical paper-pencil formatted survey was distributed to church, garden, and social and community service groups within Texas and parts of the mid-western United States. The goal from the inclusion of the paper-pencil surveys was to round out the sample to include participants of different ages, economic background, and, therefore, diversify the sample; given studies have found that samples drawn from the internet can sometimes be less inclusive (Nolan et al., 2012). These paper-pencil survey groups were selected for participation based on their ease of accessibility and interest level in participating in the study. The researchers oversaw administration of the surveys to all groups of participants. Participants were offered a free packet of wildflower seeds as an incentive to take part in the survey.

InSTRUMENTATION. The survey used for this study consisted of five sections which were modified from previous instruments and all tested for validity by being shown to a panel of experts. Participants began by differentiating themselves as gardeners or nongardeners by responding "yes" or "no" to the survey question, "do you garden?" Participants were also asked to indicate what types of gardening they performed: "ornamental," "vegetable," and/or "lawn maintenance." This question was used in a previous study (Waliczek et al., 2005).

GARDENING TIME AND ACTIVITIES SURVEY SECTION AND SCORING. A gardening activity survey was answered only by participants who answered "yes" to the question, "do you garden?" The gardening activity section consisted of eight questions pertaining to seasonality, duration, and frequency of gardening tasks performed during winter, spring, summer, and fall as well as the type of gardening and lawn maintenance tasks performed while gardening at any time. For the frequency and duration questions relating to the different seasons, participants responded by checking from a list of responses ranging from "most days" to "never" for frequency and "<30 min" to "more than 1 hour" for duration. For the questions concerning gardening and lawn maintenance, participants responded by checking all answers that applied from a given list. Response options included, "hand weeding," "mulching," "raking," and "fertilizing the lawn with a hand spreader" among others. The frequency and duration questions were modified from a previously used frequency and duration survey to encompass activities conducted in all four season. The reliability of the survey in the previous study was 0.87 (Hammond et al., 2009).

Physical activities survey SECTION AND SCORING. The next section of the survey consisted of two questions pertaining to physical exercise other than gardening. These questions were answered by all participants. The first question asked participants to control any physical activities from a given list in which they participated. Answers included "jogging," "swimming," "yoga," and "dancing" among others. The second question was an open-ended question asking participants to write in any activities in which they engaged which were not included in the list. The exercise questions were an expanded version of an exercise habit survey list used in a previous study, and were found to have a reliability of 0.77 in the previous study (Sallis et al., 1993).

Chronic ILlness SURVEY SECTION AND SCORING. The third section of the survey asked participants to indicate any recurring medical conditions from a list of 43 options. Examples of answers included, "dizziness," "chest pain," "trouble sleeping," and "high cholesterol," as well as a blank space to write in medical conditions not listed. This list was an expanded version of an illness list used in a previous study concerning health and perceptions of nature and was found to have a reliability of 0.87 in the previous study (Hammond et al., 2009).

Allergy SURVey SECTION AND scorING. Participants were asked to respond to three questions pertaining to having been diagnosed with allergies, allergy medications, and allergy symptoms in the past 12 months. These questions were a modified version of an allergy survey used in a previous study where it was found to have a reliability of 0.84 . Slight alterations to the phrasing of questions were made to accommodate this particular study and sample group (Annesi-Maesano et al., 2002). Participants were asked to answer either "yes" or "no" to questions such as, "have you had allergy symptoms in the past 12 months?" and "Do you take any medication for nasal allergies (hay fever), sinus disease, and/or allergic rhinitis?"

INSTRUMENT SCORING. Data were then transferred to $\mathrm{Excel}^{\mathrm{TM}}$ (Microsoft, Redmond, WA) where raw scores were converted to a 100point scale for each participant. Raw scores were converted by taking the points individual participants received in selected categories and dividing by the total amount of points possible in each category. A frequency of times spent gardening score was summed for each participant with 0 indicating no gardening at any time during any of the four seasons and 36 indicating the greatest amount of time spent gardening during the four seasons, with a median score of 18. A total physical gardening activity score was also calculated for each participant. Participants received one point for indicating interaction in each individual activity, resulting in a raw score on the test instrument ranging from 0 to 
20. In addition, a total activity/exercise score was calculated for each participant. Participants received one point for indicating interaction in each individual activity, resulting in a raw score on the test instrument ranging from 0 to 12 . A total health score was calculated for each participant. In determining this score, participants received one point for indicating reoccurring symptoms for each individual illness, resulting in a raw score on the test instrument ranging from 0 to 43 . Lastly, a total allergy score was calculated for each participant. Participants received one point for answering "yes" to each individual question resulting in a raw score on the test instrument ranging from 0 to 3 .

DEM OGRAPHICS SURVEY SECTION. The last section of the survey gathered demographic information and included seven questions regarding the participants' gender, age, weight and height (BMI), ethnicity, education level, state of residence, and description of residence (rural, suburban, urban, or inner city). Individual BMIs were grouped into four separate BMI categories: underweight $(<18.5)$, normal weight (18.5-24.9), overweight (25.0-29.9), and obese (30.0 or greater). The demographics section was a modified and valid version from a previously used study (Dravigne et al., 2008).

Data analysis. Data were entered and analyzed using SPSS Statistics (version 20.0 for Windows; IBM Corp., Armonk, NY). Descriptive statistics, frequencies, analysis of variance (ANOVA), multivariate ANOVA, and regression analysis tests were used to determine if there were differences in ways participants answered questions on the gardening, physical activity/ exercise, medical history, and allergy history, as well as to make demographic comparisons among respondents.

\section{Results}

A total of 1015 surveys were collected over a 4-month period. Initially, ANOVA tests found there were significant differences in age and ethnicity in the sample comparisons of gardeners and nongardeners. To balance the sample demographically, 174 participants in the 18-29 years age range who were Caucasian were removed from the study leaving 841 participants, 442 of which were gardeners, and 399 nongardeners. Data on ethnicity remained statistically significantly different after the removal of participants because a majority of the 84l participants (679) were Caucasian. The majority of overall participants were female [497 $(59.2 \%)]$, between the ages of 18 and 29 years [305 $(36.4 \%)$ ], of normal weight $[441(53.4 \%)]$, had an annual household income greater than $\$ 95,000[169(20.7 \%)]$, and had a college degree [292 (35.0\%)]. The demographics of gardeners for this study closely aligns with past research, which found the most common individual growing food to be females with college degrees living in higher annual household income homes (Butterfield, 2009). However, the overall age for this study was younger than the average age of most gardeners.

Results Related to ACTIVITY LEVELS OF GARDENERS AND NONGARDENERS. ANOVA results indicated a statistically significant difference for overall physical activity/ exercise scores between gardeners and nongardeners $[P=0.001$ (Table 1)]. Descriptive tests indicated gardeners had overall physical activity/ exercise raw scores ranging from 0 to 26 ; nongardeners had overall physical activity/exercise raw scores ranging from 0 to 12 (Table 1 ). These findings indicate gardeners participated in more types of physical activity/exercise. This supports past research which found participants reporting being more physical active after taking up gardening activities (Boyer et al., 2002). Furthermore, past research has found gardeners were more likely to meet physical activity recommendations when compared with the general population (Hawkins et al., 2013).

Results Related TO THE RELATIONSHIP OF FREQUENCY OF GARDENING AND BMI OF GARDENERS. ANOVA results indicated frequency of gardening did not have a statistically significant difference on gardeners' BMIs $(P=0.825)$. Descriptive statistics found gardeners overall BMI mean score to be 25.21 (Table 2), or, on average, slightly overweight (normal weight BMI = 18.5-24.9). Gardener BMIs were slightly lower when compared with the mean BMI of the study population (25.34). In addition, a linear regression analysis was conducted which indicated no statistically significant relationship between the frequency of gardening activities and BMI scores of gardeners $[P=0.736$ (Table 3)].

Results Related TO THe DIFFERENCE IN BMI OF GARDENERS AND NONGARDENERS. ANOVA results indicated no statistically significant difference between BMI scores of gardeners when compared with nongardeners $(P=0.807)$. Descriptive tests found the overall mean BMI score for the study to be 25.34 (overweight 25.029.9). Descriptive statistics showed that nongardeners' overall mean BMI score was slightly above the overall mean BMI score (Table 2), whereas gardeners' overall mean BMI score was slightly below the overall mean BMI score. However, in this study, there was not enough evidence to support past research which found gardeners were more prone to have lower BMI scores when compared with those not involved in gardening (Zick et al., 2013). Demographically the sample population of gardeners was matched to nongardners but, overall, the sample group was young (18-30 years) and in the age range with the lowest incidence of overweight and obesity issues (CDC, 2014). These findings indicate individuals of all sizes are drawn to the activity of gardening (Park et al., 2014).

RESULTS RELATED TO DIFFERENCES IN REPORTED OVERALL HEALTH OF GARDENERS AND NONGARDENERS. ANOVA results indicated no statistically significant

Table 1. Analysis of variance comparison and descriptive statistics of overall mean physical activity/exercise scores of gardeners and nongardeners.

\begin{tabular}{lcccccc}
\hline Dependent variable & $\mathbf{N}$ & $\begin{array}{c}\text { Overall physical } \\
\text { activity/exercise score }^{\mathrm{z}}\end{array}$ & SD & df & $\boldsymbol{F}$ & $\boldsymbol{P}$ \\
\hline Total & 841 & 25.31 & 5.61 & 1 & $1,390.548$ & $0.001^{*}$ \\
Gardeners & 552 & 38.46 & & & & \\
Nongardeners & 399 & 10.71 & & & & \\
\hline
\end{tabular}

${ }^{\mathrm{z}}$ Participants received a raw score on the test instrument ranging from 0 to 32 . Participants received one point for indicating interaction in each individual activity/exercise. Higher scores indicated more activity. For the purpose of analysis and discussion, these raw scores were converted to a 100 -point scale.

* Significant at $P \leq 0.05$ 
Table 2. Analysis of variance comparison and descriptive statistics of gardeners and nongardeners body mass index (BMI) scores and overall mean BMI score in BMI categories: underweight, normal weight, overweight, and obese.

\begin{tabular}{lrccccc}
\hline BMI categories & $\mathbf{n}^{\mathbf{y}}$ & Mean BMI score & sD & df & $\boldsymbol{F}$ & $\boldsymbol{P}$ \\
\hline Overall underweight & 34 & 17.39 & 0.88 & 1 & 0.000 & 0.988 \\
$\quad$ Gardeners & 21 & 17.39 & 0.90 & & & \\
$\quad$ Nongardeners & 13 & 17.40 & 0.88 & & & \\
Overall normal weight & 441 & 21.86 & 1.78 & 1 & 0.040 & 0.842 \\
$\quad$ Gardeners & 222 & 21.88 & 1.73 & & & \\
Nongardeners & 219 & 21.84 & 1.84 & & & \\
Overall overweight & 206 & 26.99 & 1.46 & 1 & 1.494 & 0.223 \\
Gardeners & 124 & 26.89 & 1.47 & & \\
$\quad$ Nongardeners & 82 & 27.15 & 1.46 & & \\
Overall obese & 145 & 35.45 & 4.67 & 1 & 3.255 & 0.073 \\
$\quad$ Gardeners & 73 & 34.76 & 4.64 & & \\
$\quad$ Nongardeners & 72 & 36.15 & 4.64 & & & \\
Mean BMI scores & & & & & \\
$\quad$ Gardeners overall BMI & 440 & 25.21 & 5.49 & & & \\
$\quad$ Nongardeners overall BMI & 386 & 25.49 & 6.16 & & \\
Overall mean BMI & 826 & 25.34 & 5.81 & & \\
\hline
\end{tabular}

${ }^{\mathrm{z}}$ Individual BMIs were grouped into four separate BMI categories: underweight $(<18.5)$, normal weight $(18.5-$ $24.9)$, overweight (25.0-29.9), and obese (30.0 or greater). ${ }^{\mathrm{y}} \mathrm{N}=826$.

Table 3. Linear regression analysis indicating the correlation between frequency of gardening and body mass index (BMI) score, overall health score, and overall allergy score for gardeners in the study of the influence of gardening activities on self-reported health problems, allergies, and BMI.

\begin{tabular}{llc}
\hline Dependent variable & \\
\hline BMI score $^{\mathrm{z}}$ & Pearson correlation & 0.077 \\
& $P$ & 0.736 \\
Overall health score $^{\mathrm{y}}$ & $\mathrm{N}$ & 439 \\
& Pearson correlation & 73.435 \\
& $P$ & 0.088 \\
Overall allergy score $^{\mathrm{x}}$ & $\mathrm{N}$ & 441 \\
& Pearson correlation & 0.088 \\
& $P$ & 0.805 \\
\hline
\end{tabular}

${ }^{\mathrm{z}}$ Individual BMIs were grouped into four separate BMI categories, underweight $(<18.5)$, normal weight $(18.5-$ $24.9)$, overweight (25.0-29.9), and obese (30.0 or greater).

${ }^{\mathrm{y}}$ Participants received a raw score on the test instrument ranging from 0 to 43 ; participants received one point for indicating reoccurring symptoms for each individual illness. For the purpose of analysis and discussion, these raw scores were converted to a 100 -point scale.

"Participants received one point for answering "Yes" to each individual question. For the purpose of analysis and discussion, these raw scores were converted to a 100-point scale.

differences between overall health scores of gardeners compared with nongardeners $(P=0.492)$. Descriptive tests indicated gardeners had an overall mean health score of 11.67 . Nongardeners had an overall mean health score of 11.30. Descriptive tests found the overall mean health score for the study to be 11.58 . Nongardeners' overall mean health score was slightly below the overall mean health score. Gardeners' overall mean health score was slightly above the overall mean health score.

ANOVA results found statistically significant differences for five chronic illnesses: "ear infection/ear ache" $(P=0.013)$, "high cholesterol" $(P=0.048)$, "kidney stone" $(P=$ $0.032)$, "gallstones" $(P=0.017)$, and "arthritis" $(P=0.016)$ (Table $4)$. Frequency statistics indicated gardeners were more likely to list having reoccurring symptoms for each of these chronic illnesses when compared with nongardeners (Table 4).

The fact that gardeners had higher incidences of certain chronic illness may suggest a link to past research, which found plants and scenes of nature can be used as a form of distraction therapy, which can significantly reduce perceived pain, the amount of pain medication needed, anxiety, fatigue, and allow individuals to feel more wakefully relaxed (Diette et al., 2003; Park and Mattson, 2008; Ulrich, 1981). Gardeners with chronic illness may be drawn to gardening because it is a form of physical activity in which they can comfortably participate in a convenient nonjudgmental atmosphere.

RES U L T S RE L A T E D T O DIFFERENCES IN REPORTED INCIDENCE OF ALLERGIES BETWEEN GARDENERS AND NONGARDENERS. ANOVA results indicated there were no significant differences in incidence of allergies between gardeners and nongardeners $(P=0.351)$. For the purpose of analysis and discussion, raw scores were converted to a 100 -point scale. Descriptive tests indicated the overall mean allergy score to be 40.33 . Gardeners had a total allergy score slightly higher when compared with the mean allergy score of the study (41.00). Nongardeners had a slightly lower total allergy score from the mean allergy score of the study (39.66).

Despite spending more time outdoors during seasons when pollen is abundant, gardeners were not found to have any differences in allergies when compared with nongardeners. Past research has found several causes of seasonal allergies to be tree, grass and weed pollen, and outdoor mold spores (Skoner, 2001). Furthermore, research found individuals exposed to farming environments in their early childhood have less frequent occurrences of asthma, hay fever and atopic eczema (Riedler et al., 2001).

FREQUENCY OF GARDENING AND GARDENERS' OVERALL HEALTH AND ALLERgY INCIDENCE. Comparisons were made among gardeners based on their frequency of gardening and their incidence of allergies and other chronic health symptoms/overall health scores using a linear regression analysis. No statistically significant correlations were found between frequency of gardening and overall health scores $[P=0.088$ (Table 3 )], or frequency of gardening and overall allergy scores $[P=0.805$ (Table 3$)]$. These findings supported those found earlier in comparisons of gardeners and nongardeners.

DEMOgRAPHIC COMPARISONS. Demographic groups of gardeners were compared with determine if any group benefited more within any variables of interest. A multivariate 
Table 4. Analysis of variance comparison and frequency statistics for individual chronic illnesses for gardeners and nongardeners in the study the influence of gardening activities on self-reported health problems, allergies, and body mass index.

\begin{tabular}{|c|c|c|c|c|c|c|c|c|}
\hline Dependent variable & $\begin{array}{l}\text { Gardeners } \\
(\text { no. })^{\mathrm{z}}\end{array}$ & $\begin{array}{c}\text { Gardeners } \\
(\%)\end{array}$ & $\begin{array}{l}\text { Nongardeners } \\
(\text { no. })^{\mathrm{y}}\end{array}$ & $\begin{array}{c}\text { Nongardeners } \\
(\%)\end{array}$ & SD & df & $F$ & $P$ \\
\hline $\begin{array}{l}\text { Limitations in any of the following } \\
\text { activities due to health problems: } \\
\text { riding a bike, running, or playing } \\
\text { sports? }\end{array}$ & 87 & 19.7 & 59 & 14.8 & 0.37 & 1 & 3.510 & 0.061 \\
\hline Dizziness & 86 & 19.5 & 66 & 16.5 & 0.38 & 1 & 1.203 & 0.273 \\
\hline Chest pain & 35 & 7.9 & 22 & 5.5 & 0.25 & 1 & 1.919 & 0.166 \\
\hline Neck pain & 53 & 12.0 & 55 & 13.8 & 0.33 & 1 & 0.602 & 0.438 \\
\hline Back pain & 152 & 34.4 & 116 & 29.1 & 0.46 & 1 & 2.732 & 0.099 \\
\hline Frequently swollen glands & 7 & 1.6 & 14 & 3.5 & 0.15 & 1 & 3.196 & 0.074 \\
\hline Cough & 51 & 11.5 & 55 & 13.8 & 0.33 & 1 & 0.959 & 0.328 \\
\hline Short of breath & 81 & 18.3 & 71 & 17.8 & 0.38 & 1 & 0.040 & 0.842 \\
\hline Asthma attacks & 47 & 10.6 & 31 & 7.8 & 0.29 & 1 & 2.012 & 0.156 \\
\hline Itchy watery eyes & 74 & 16.7 & 50 & 12.5 & 0.35 & 1 & 2.961 & 0.086 \\
\hline Colds & 63 & 14.3 & 60 & 15.0 & 0.35 & 1 & 0.103 & 0.748 \\
\hline Nasal congestion & 92 & 20.8 & 87 & 21.8 & 0.40 & 1 & 0.122 & 0.724 \\
\hline Ear infection or each ache & 39 & 8.8 & 18 & 4.5 & 0.25 & 1 & 6.203 & $0.013^{*}$ \\
\hline Sore throat & 53 & 12.7 & 51 & 12.8 & 0.33 & 1 & 0.002 & 0.961 \\
\hline Anxiety & 147 & 33.3 & 122 & 30.6 & 0.46 & 1 & 0.692 & 0.406 \\
\hline Loss of appetite & 37 & 8.4 & 39 & 9.8 & 0.28 & 1 & 0.502 & 0.479 \\
\hline Sleep apnea & 14 & 3.2 & 16 & 4.0 & 0.18 & 1 & 0.432 & 0.511 \\
\hline Depression & 140 & 31.7 & 135 & 33.8 & 0.46 & 1 & 0.444 & 0.505 \\
\hline Felling tired having low energy & 171 & 38.7 & 158 & 39.6 & 0.48 & 1 & 0.073 & 0.787 \\
\hline Trouble sleeping & 105 & 23.8 & 113 & 28.3 & 0.43 & 1 & 2.277 & 0.132 \\
\hline High cholesterol & 18 & 4.1 & 7 & 1.8 & 0.16 & 1 & 3.915 & 0.048 * \\
\hline Kidney stone & 10 & 2.3 & 2 & 0.5 & 0.11 & 1 & 4.639 & 0.032 * \\
\hline Kidney failure & 1 & 0.2 & 2 & 0.5 & 0.05 & 1 & 0.445 & 0.505 \\
\hline Anemia & 32 & 7.2 & 22 & 5.5 & 0.24 & 1 & 1.039 & 0.308 \\
\hline Blood clot & 2 & 0.5 & 0 & 0.0 & 0.04 & 1 & 1.809 & 0.179 \\
\hline Gout & 3 & 0.7 & 1 & 0.3 & 0.06 & 1 & 0.811 & 0.368 \\
\hline Ulcers & 8 & 1.8 & 8 & 2.0 & 0.13 & 1 & 0.043 & 0.836 \\
\hline Gallstones & 9 & 2.0 & 1 & 0.3 & 0.10 & 1 & 5.716 & $0.017^{*}$ \\
\hline Pancreatitis & 4 & 0.9 & 0 & 0.0 & 0.06 & 1 & 3.635 & 0.057 \\
\hline Osteoporosis & 1 & 0.2 & 3 & 0.8 & 0.06 & 1 & 1.223 & 0.269 \\
\hline Arthritis & 26 & 5.9 & 10 & 2.5 & 0.20 & 1 & 5.860 & $0.016^{*}$ \\
\hline
\end{tabular}

${ }^{\mathrm{z}} \mathrm{N}=442$.

${ }^{\mathrm{y}} \mathrm{N}=399$.

* Statistically significant at $(P \leq 0.05)$

ANOVA test was used to analyze differences in overall physical activity/exercise scores, total health scores, total allergy scores, and BMIs based on demographics of gardeners. Among gardeners of different genders, age, education level, and ethnicity, there were no differences in activity levels, health problems, and incidence of allergies. Gardening appears to be an activity that can benefit all similarly. This is supported by past research, that found gardening to cross demographic characteristics and benefit groups from all age, gender, education level, and ethnicity
(Alaimo et al., 2008; Boyer et al., 2002; Peeters et al., 2014; Sommerfeld et al., 2010).

\section{Discussion}

Results from this study indicated gardeners reported more physical activity when gardening was considered 
as a form of exercise. This supported past research, that found participants to report "being more physical active" after taking up gardening activities (Boyer et al., 2002). However, no statistically significant differences were found in BMI scores, incidence of allergies or overall health scores of gardeners and nongardeners. The lack of differences in BMI scores between gardeners and nongardeners may be due to the majority of the sample population being younger (18-30 years). Research has found that overweight and obesity is more prevalent in middle-aged people between the ages 40 and 59 years (CDC, 2014) and these findings may vary in an older sample population.

Results were found in incidence of five specific chronic illnesses with gardeners reporting them more often. This finding may suggest a link to past research which found plants and scenes of nature to be beneficial as a form of distraction therapy, which can significantly reduce pain, the amount of pain medication needed, anxiety, and fatigue in individuals (Diette et al., 2003; Park and Mattson, 2008). Past research has found $30.7 \%$ of the U.S. population has moderate to severe chronic pain, of which $89.0 \%$ has experienced chronic pain for over 1 year. In addition, $86.0 \%$ of chronic pain sufferers experience pain at least two to three times per week (Johannes et al., 2010). Some chronic pain sufferers become overly focused on their pain, causing them to become fixed in a recurrent pattern of thought and action, which limit their overall function. Mindfulness, defined as the practice of broad, present-focused neutral awareness, can be used to observe physical and emotional symptoms in such a way that automatic responses to thought patterns can be reduced (McCracken et al., 2007).

Kaplan and Kaplan (1989) proposed reconnecting with nature helps a person to reach four central aspects needed for restoration, reducing mental fatigue: 1) "being away" involves seeking a method to be away from the current situation causing mental fatigue; 2) "extent," involves the extent to which a place is rich and coherent enough to constitute a whole other world which can be attained physically or perceptually; 3 ) "fascination" is something a person finds interesting and meaningful, but does not require direct attention; and 4) "compatibility" is an environment supportive of behavior and helps to reduce mental fatigue (Kaplan and Kaplan, 1989). This would suggest tasks such as gardening can potentially be useful in helping people with chronic pain begin to change their thought patterns on how they perceived pain.

Much of the research conducted on gardeners focuses on the benefits to the general health and well-being gardening has to individuals instead of drawing conclusions on specific illnesses (Schmutz et al., 2014). Gardening has been found to increase physical activity and fruit and vegetable consumption, both of which are recommended to reduce the risks of certain chronic illnesses. Chronic illness can lead to depression, which can worsen a person's overall health (Moussavi et al., 2007). Research has found gardening can help to reduce depression in individuals with disabilities and increase overall life satisfaction (Waliczek et al., 2005; Wilson and Christensen, 2011).

Among gardeners of different genders, age, education level, and ethnicity, there were no differences in activity levels, health problems and incidence of allergies. Gardening appears to be an activity that can benefit all similarly. This is supported by past research that found gardening to cross demographic characteristics and benefit groups from all age, gender, education level and ethnicity (Alaimo et al., 2008; Boyer et al., 2002; Peeters et al., 2014; Sommerfeld et al., 2010).

Recommendations for future research include analyzing an older participants sample to determine if results vary and conducting a more in-depth study on gardeners with chronic illnesses and perceptions of quality of life and incidence of diagnoses of depression symptoms.

\section{Literature cited}

Alaimo, K., E. Packnett, R.A. Miles, and D.J. Kruger. 2008. Fruit and vegetable intake among urban community gardeners. Nutr. Educ. Behavior 40:94-101.

American Academy of Allergy, Asthma and Immunology (AAAAI). 2015. Allergy statistics. 29 July 2015. <http:// www.aaaai.org/media/resources/ media_kit/allergy_statistics.stm>.
Annesi-Maesano, I., A. Didier, M. Klossek, I. Chanal, D. Moreau, and J. Bousquet. 2002. The score for allergic rhinitis (SFAR): A simple and valid assessment method in population studies. Allergy 57:107-114.

Bielory, L., D.P. Skoner, M.S. Blaiss, B. Leatherman, M.S. Dykewicz, N. Smith, G. Ortiz, J.A. Hadley, N. Walstein, T.J. Craig, and F. Allen-Ramey. 2014. Ocular and nasal allergy symptom burden in America: The allergies, immunotherapy, and rhino conjunctivitis (AIRS) surveys. Allergy Asthma Proc. 35:211-218.

Boyer, R., T.M. Waliczek, and J.M. Zajicek. 2002. The master gardener program: Do benefits of the program go beyond improving the horticultural knowledge of the participants? HortTechnology 12:432-436.

Burges-Watson, D.L. and H.J. Moore. 2011. Community gardening and obesity. Perspect. Public Health 131:163-164.

Butterfield, B. 2009. The impact of home and community gardening in America. Natl. Gardening Assn., Burlington, VT.

Carney, P.A., J.L. Hamada, R. Rdesinski, L. Sprager, K.R. Nichols, B.Y. Liu, J. Pelayo, M.A. Sanchez, and J. Shannon. 2011. Impact of community gardening project on vegetable intake, food security and family relationships: A communitybased participatory research study. J. Community Health 37:874-881.

Centers for Disease Control and Prevention (CDC). 2007. Prevalence of regular physical activity among adultsUnited States 2001-2005. Morb. Mortal. Wkly. Rpt. 56:1209-1212.

Centers for Disease Control and Prevention (CDC). 2014. Overweight and obesity. 15 June 2014. <http://www. cdc.gov/obesity/data/adult.html>.

Coban, H. and Y. Aydemir. 2014. The relationship between allergy and asthma control, quality of life, and emotional status in patients with asthma: A crosssectional study. Allergy Asthma Clin. Immunol. 10:67-79.

Diette, G.D., N. Lechtzin, E. Haponik, A. Devrotes, and H.R. Rubin. 2003. Distraction therapy with nature sights and sounds reduces pain during flexible bronchoscopy: A complementary approach to routine analgesia. Chest J. 123:941-948.

Dravigne, A., T.M. Waliczek, R.D. Lineberger, and J.M. Zajicek. 2008. The effect of live plants window views of green spaces on employee perceptions of job satisfaction. HortScience 43:183-187.

Hammond, D., T.M. Waliczek, and J.M. Zajicek. 2009. The relationship between 
parental attitudes about children spending time outdoors and their children's overall health. HortTechnology 21:217224.

Haskell, W.L., I.M. Lee, R.R. Pate, K.E. Powell, S.N. Blair, B.A. Franklin, C.A. Macera, G.W. Heath, P.D. Thompson, and A. Bauman. 2007. Physical activity and public health: Updated recommendations for adults from the American College of Sports Medicine and the American Heart Association. Circulation 116:1081-1093.

Hawkins, J.L., J. Mercer, K.J. Thirlaway, and D.A. Clayton. 2013. "Doing" gardening and "being" at the allotment site: Exploring the benefits of allotment gardening for stress reduction and healthy aging. Ecopsychology 5:110-125.

Johannes, C.B., T.K. Le, X. Zhou, J.A. Johnston, and R.H. Dworkin. 2010. The prevalence of chronic pain in United States adults: Results of an internet-based survey. J. Pain 11:1230-1239.

Kaplan, S. and R. Kaplan. 1982. Cognition and environment. Praeger, New York, NY.

Kaplan, R. and S. Kaplan. 1989. The experience of nature: A psychological perspective. Cambridge Univ. Press, New York, NY.

Kopelman, P.G. 2000. Obesity as a medical problem. Nature 404:635-643.

Lake, A. and T. Townshend. 2006. Obesogenic environments: Exploring the built and food environments. J. R. Soc. Promot. Health 126:262-267.

Langellotto, G.A. and A. Gupta. 2012. Gardening increases vegetable consumption in school-aged children: A metaanalysis synthesis. HortTechnology $22: 430-445$

McCracken, L.M., J. Gauntlett-Gilbert, and K.E. Vowles. 2007. The role of mindfulness in contextual cognitive-behavioral analysis of chronic pain-related suffering and disability. J. Pain 131:6369.

Moussavi, S., S. Chatterji, E. Verdes, A. Tandon, V. Patel, and B. Ustun. 2007. Depression, chronic diseases, and decrements in health: Results from the world health surveys. World Health Org. 370:851-858.

Nelson, M.E., W.J. Rejeski, S.N. Blair, P. W. Duncan, J.O. Judge, A.C. King, C.A. Macera, and C. Castaneda-Sceppa. 2007. Physical activity and public health in older adults: Recommendation from the American College of Sports Medicine and the American Heart Association. Med. Sci. Sports Exerc. 39:1435-1445.

Nolan, G. A., McFarland, J.M. Zajicek, and T.M. Waliczek. 2012. The effects of nutrition education and gardening on attitudes, preferences and knowledge of 2nd-5th graders toward fruit and vegetables. HortTechnology 22:299-304.

Nykamp, J. 1999. Gardening improves physical health, well-being. 10 Jan. 2014. <http://www.hollandsentinel.com/ stories/010199/fea_gardening.html>.

Ogden, C.L., M.D. Carroll, L.R. Curtin, M.A. McDowell, C.J. Tabak, and K.M. Flegal. 2006. Prevalence of overweight and obesity in the United States, 19992004. J. Amer. Medical Assn. 295:15491555 .

Park, S.H. and R.H. Mattson. 2008. Effects of flowering and foliage plants in hospital rooms on patience recovering from abdominal surgery. HortTechnology 18:563-568.

Park, S., A. Lee, K. Lee, and K. Son. 2014. Gardening tasks performed by adults are moderate to high intensity physical activities. HortTechnology 24:58-63.

Pate, R.R., M. Pratt, S.N. Blair, W.L. Haskell, C.A. Macera, C. Bouchard, D. Buchner, W. Ettinger, G.W. Heath, A.C. King, A. Kriska, A.S. Leon, B.H. Marcus, J. Morris, R.S. Paffenbarger, Jr., K. Patrick, M.L. Pollock, J.M. Rippe, J. Sallis, and J. H. Wilmore. 1995. Physical activity and public health: A recommendation from the Centers for Disease Control and Prevention and the American College of Sports Medicine. J. Amer. Medical Assn. 273:402-407.

Peeters, G., Y.R. Van Gellecum, J.G.Z. Van Uffelen, N.W. Burton, and W.J. Brown. 2014. Contribution of house and garden work to the association between physical activity and well-being in young, mid-aged and older women. J. Sports Med. 48:996-1001.

Riedler, J., C. Braun-Fahrlander, W. Eder, M. Schreuer, M. Waser, S. Maisch, D. Carr, R. Schierl, D. Nowak, and E. Von Mutius. 2001. Exposure to farming in early life and development of asthma allergy: A cross-sectional survey. Lancet 358:1129-1133.

Sallis, J.F., M.J. Buono, J.J. Roby, F.G. Micale, and J.A. Nelson. 1993. Seven-day recall and other physical activity self-reports in children and adolescents. Med. Sci. Sports Exerc. 25:99-108.

Schmutz, U., M. Lennartsson, S. Williams, M. Devereaux, G. Davies, and T. Lang.
2014. The benefits of gardening and food growing for health and wellbeing. Garden Organic, London, UK.

Singh, K., S. Axelrod, and L. Bielory. 2010. The epidemiology of ocular and nasal allergy in the United States, 19881994. J. Allergy Clin. Immunol. 126:778-783.

Skoner, D.P. 2001. Allergic rhinitis: Definition, epidemiology, pathophysiology, detection, and diagnosis. J. Allergy Clin. Immunol. 108:2-8.

Sommerfeld, A.J., A.L. McFarland, T.M. Waliczek, and J.M. Zajicek. 2010. Growing minds: Evaluating the relationship between gardening and fruit and vegetable consumption in older adults. HortTechnology 20:711-717.

Taylor, M.K. 1990. The healthy gardener. Flower Garden 1990(Mar):46-47.

Turner, L.W., M.A. Bass, L. Ting, and B. Brown. 2002. Influence of yard work and weight training on bone mineral density among older U.S. women. J. Women Aging 14:139-145.

Ulrich, R.S. 1981. Natural versus urban scenes: Some psychophysiological effects. Environ. Behav. 13:523-556.

U.S. Department of Health and Human Services (HHS). 2001. The Surgeon General's call to action to prevent and decrease overweight and obesity. 5 Jan. 2014. <http://www.surgeongeneral. gov/topics/obesity/calltoaction/cover. htm>.

U.S. Department of Health and Human Services (HHS). 2008. The President's Council on Physical Fitness and Sports. 5 Jan. 2014. <http://www.fitness.gov/ resources_factsheet.htm $>$.

Waliczek, T.M., J.M. Zajicek, and R.D. Lineberger. 2005. The influence of gardening activities on consumer perceptions of life. HortScience 40:1360-1365.

Weisberg, S.P. 2002. Societal change to prevent obesity. 10 Jan. 2014. <http:// www.ama-assn.org/sci-pubs/msjama/ articles/vol_288/no_17/jms1 106021 . htm>.

Wilson, J.F. and K.M. Christensen. 2011. The relationship between gardening and depression among individuals with disabilities. J. Therapeutic Hort. 21:29-41.

Zick, C.D., K.R. Smith, L.K. Jones, C. Uno, and B.J. Merrill. 2013. Harvesting more than vegetables: The potential weight control benefits of community gardening. Amer. J. Public Health 103:1110-1150. 